\title{
Out with the old and in with the new: Hepatic fibrosis assessment in Canada
}

\author{
Natasha Chandok MD MPH FRCPC
}

A rapid, reliable test, also acceptable to patients for the assessment of liver fibrosis, has long been the 'holy grail' of hepatology. The now dusty liver textbooks of yesteryear described percutaneous liver biopsy (PLB) - an ancient procedure that must seem archaic to patients. Although PLB remains germane to the artful management and careful diagnosis of particular diseases, its role in certain entities, such as viral hepatitis, is now questionable at best since FibroTest (LabCorp, USA) and FibroScan (Echosens, France) have become available in Canada. Even among common conditions such as steatohepatitis, liver biopsy may not exceed the minimum threshold of 'changing the patient's management' to justify its execution and cost and, as such, there appears to be increasingly fewer reasons to perform it. In fact, an entire generation of hepatologists have graduated their fellowship programs of late with ineptness in PLB, and I maintain that they are none the lesser for it.

Of the gold standards, PLB is a flawed one for (at least) three reasons: most liver biopsies are inadequate in size and, thus, carry an inherent risk of inaccuracy (1); studies show a concerning interobserver variation among the pathologists who read them (1); and even if the specimen is of adequate size, diseases of the liver are all too often patchy, creating an intrinsic uncertainty in staging (2). Moreover, as a medical test, patients are, at the very least, highly inconvenienced by it, and while the majority sail through without major complications, a sufficiently high proportion of patients experience significant pain, not infrequently requiring admission to hospital or extended time away from work. Although also imperfect in head-to-head comparison studies with liver biopsy for accuracy, FibroScan and FibroTest have high F-statistics, and address many of the particular pitfalls of PLB, namely that of morbidity risk (3). As such, FibroTest and FibroScan have a primary, indisputable role to play in fibrosis assessment.

Current trends in Canadian physician practice patterns regarding PLB are well-reflected in a study published by Sebastiani et al (4) (pages 23-30) in the current issue of the Journal. They surveyed a collection of 104 physicians who are members of the Canadian Association of Gastroenterology and/or the Canadian HIV Trials Network caring for patients with liver disease; their results are both informative and largely unsurprising. The majority of survey participants, nearly twothirds of whom were gastroenterologists, required assessment of disease stage, and the greatest demand for fibrosis assessment was for patients with hepatitis $\mathrm{C}(76.9 \%)$. The authors found that noninvasive fibrosis assessment was ordered more frequently in patients with viral hepatitis than autoimmune hepatitis, likely reflecting that necroinflammatory activity of the latter is crucial information by which to guide immunosuppression. Similar to our recent study involving hepatologists who are members of the Canadian Association for the Study of the Liver (5), noninvasive modalities of fibrosis evaluation had an approximate $50 \%$ perceived reduction in the need for PLB. When one considers that PLB performed in an ambulatory setting in a hospital may cost approximately $\operatorname{CAD} \$ 1,000$ in the current era (this crude estimation includes radiology and pathology fees, but does not include costs of a $4 \mathrm{~h}$ observation time within the hospital and costs incurred by the patient), it is not difficult to surmise that in a high-volume centre, FibroTest and the FibroScan will pay for themselves in a short time.

Perhaps the most startling observation of the study by Sebastiani et al (4) was that approximately $50 \%$ of surveyed physicians continue to use PLB as the primary modality of fibrosis assessment. Some may call this necessary reliance on PLB a reflection of an antiquated Canadian health care system and an injustice to patients with liver disease. Sebastiani et al identified several physician barriers to noninvasive fibrosis testing that provide great insight into this trend, including lack of availability, inadequate or nonexistent reimbursement, and absence of evidence-based guidelines. Variations in practice patterns - and frank underutilization of noninvasive fibrosis testing - demonstrated by Sebastiani et al (4) and our own study (5) are to the detriment of patients and, in addition to the obvious concern over inequitable access to state-of-the art fibrosis testing for Canadians, the observed variation in practice patterns reflects a need for either more research into optimal fibrosis assessment pathways, more physician education or both. Finally, Canadian health care system policies should better reflect the strong evidence that FibroTest and FibroScan now occupy an indispensible role in fibrosis assessment, and broad availability, improved access and transparent, patient-sparing reimbursement channels are urgently required, in addition to spirited advocacy for better access to these novel tests by the those who manage patients with liver disease.

\section{REFERENCES}

1. Poynard T, Munteanu M, Imbert-Bismut F, et al. Prospective analysis of discordant results between biochemical markers and biopsy in patients with chronic hepatitis C. Clinical Chem 2004;50:1344-55.

2. Skripenova S, Trainer TD, Krawitt EL, Blaszyk H. Variability of grade and stage in simultaneous paired liver biopsies in patients with hepatitis C. J Clin Pathol 2007;60:321-4.

3. Poynard T, de Ledinghen V, Zarski JP, et al. Relative performances of FibroTest, Fibroscan, and biopsy for the assessment of the stage of liver fibrosis in patients with chronic hepatitis C: A step toward the truth in the absence of a gold standard. J Hepatol 2012;56:541-8.

4. Sebastiani G, Ghali P, Wong P, Klein MB, Deschenes M, Myers RP. Physicians' practices for diagnosing liver fibrosis in chroninc liver diseases. A nationwide, Canadian survey. Can J Gastroenterol Hepatol 2014;28:23-30.

5. Aljawad M, Yoshida EM, Uhanova J, Marotta P, Chandok N. Percutaneous liver biopsy practice patterns among Canadian hepatologists. Can J Gastroenterol 2013;27:e31-e34.

${ }^{1}$ Division of Gastroenterology, University of Western Ontario, London; ${ }^{2}$ Division of Gastroenterology, William Osler Health System, Brampton, Ontario

Correspondence: Dr Natasha Chandok, Division of Gastroenterology, University of Western Ontario, 339 Windermere Road, London,

Ontario N5X 2T2. Telephone 905-494-2120 ext 57994, fax 905-303-3883, e-mail nchandok@uwo.ca

Received and accepted for publication November 25, 2013 


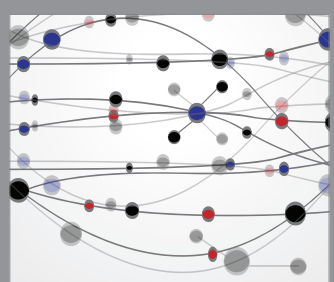

The Scientific World Journal
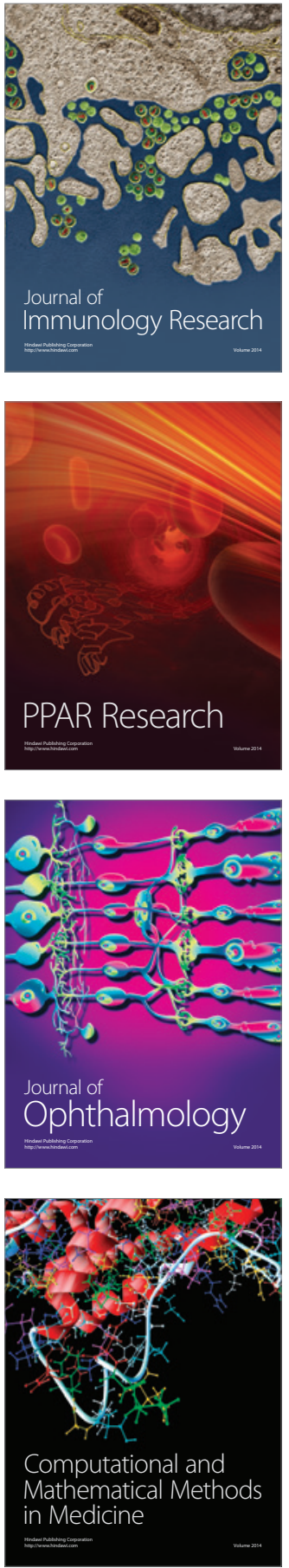

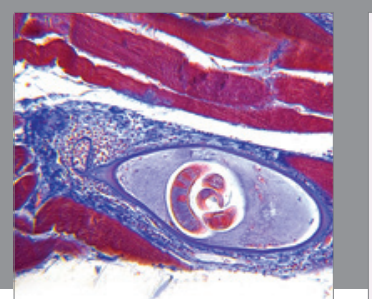

Gastroenterology Research and Practice

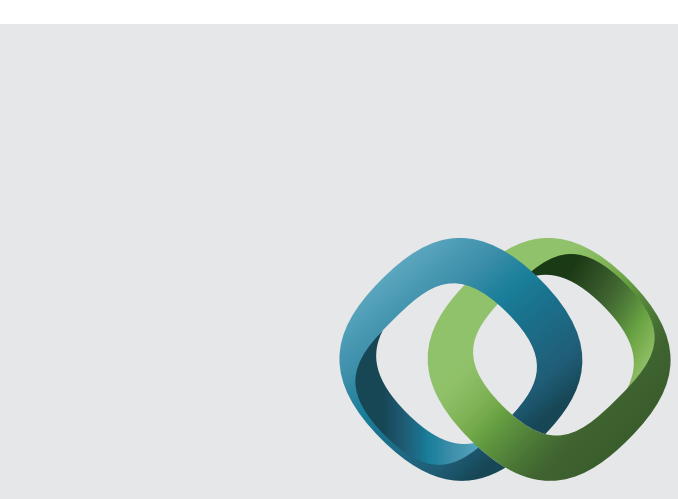

\section{Hindawi}

Submit your manuscripts at

http://www.hindawi.com
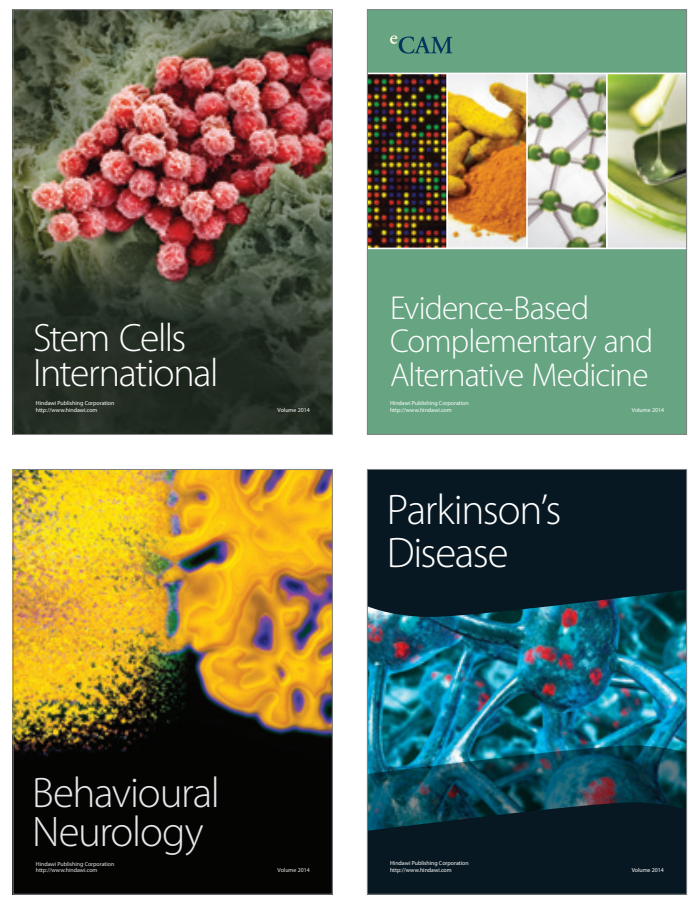
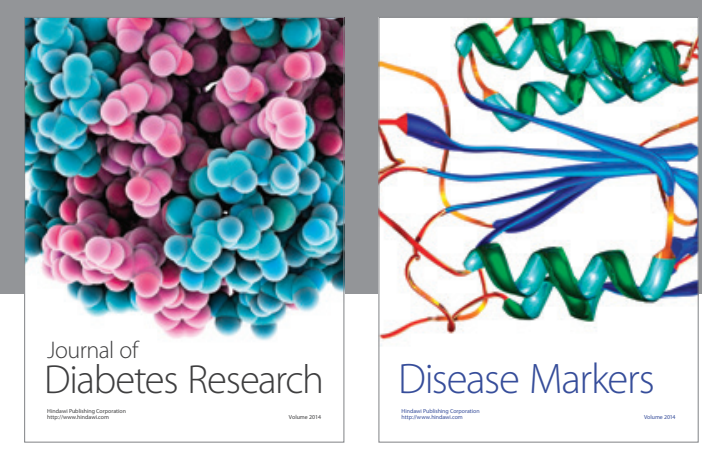

Disease Markers
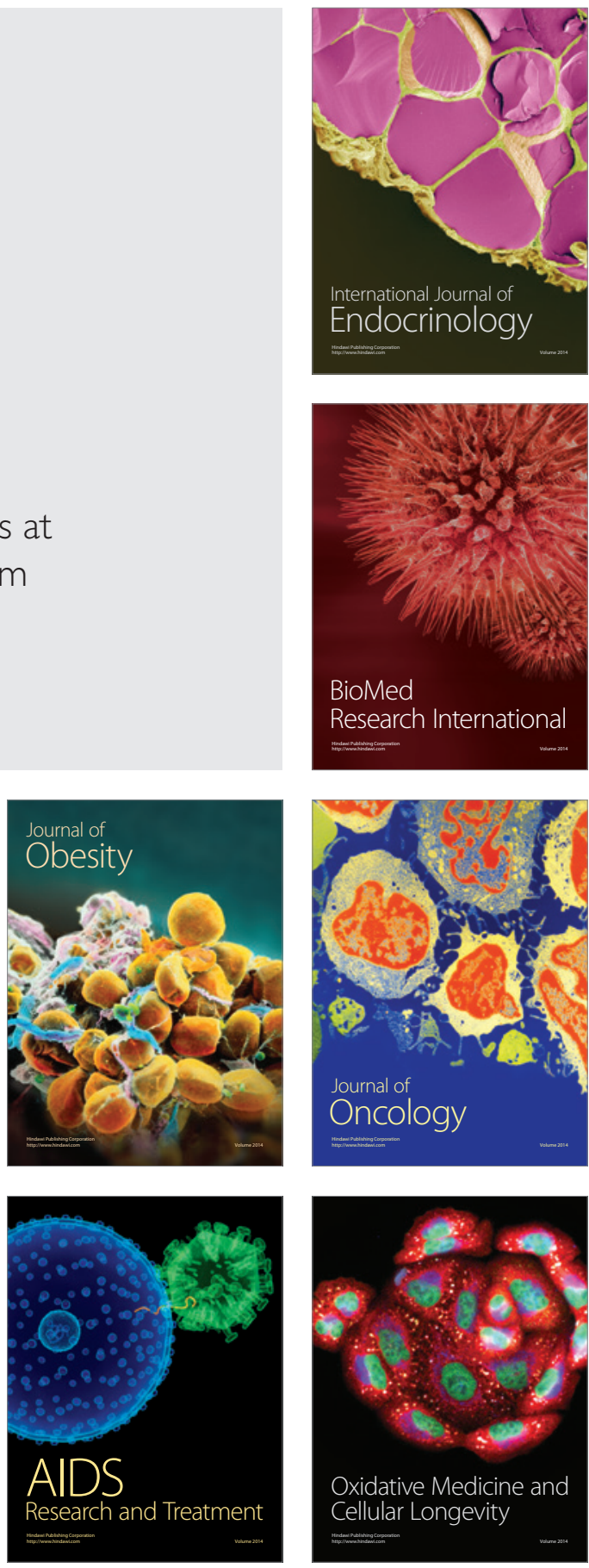